\title{
Bromate Formation by the Oxidation of Bromide in the Electrochemically Activated Persulfate Process: Mechanism and Influencing Factors
}

\author{
Feng Zhang*, Dongyi Zhang, Tong Chang, Hongyan Li, Jiali Cui, Jianguo Cui* \\ College of Environmental Science and Engineering, Taiyuan University of Technology, Taiyuan, \\ 030024, PR China; \\ *E-mail: zhangfeng@tyut.edu.cn, afh2005@163.com
}

doi: $10.20964 / 2020.08 .24$

Received: 2 April 2020 / Accepted: 11 May 2020 / Published: 10 July 2020

In this study, an electrochemically activated persulfate (EAP) process using boron-doped diamond (BDD) as the anode was adopted for the activation of peroxydisulfate (PDS) to treat bromidecontaining water. In this EAP process, the activation of PDS to generate $\mathrm{SO}_{4}{ }^{*}$ is mainly caused by direct electron transfer at the cathode. The synergetic oxidation by the free radical oxidants, including $\mathrm{OH} \bullet$ electrogenerated on the $\mathrm{BDD}$ anode and $\mathrm{SO}_{4}{ }^{-}$produced on the cathode, is the major driving force to oxidize bromide to bromate through the continuous stepwise reaction. The cathodic reduction of high-valent bromine compounds coexisting in the EAP process could also affect the distribution of bromine by-products. The bromate formed in the EAP process decreased when humic acid coexisted in the bromide-containing water because the active bromine $(\mathrm{Br} \bullet$ and $\mathrm{HOBr}$ ) could react with organic matter to form brominated by-products. Bromate formation was increased with increasing PDS dosage, initial bromide concentration and current density. An acidic environment is beneficial for inhibiting the formation of bromate, but it might also increase the risk of formation of brominated by-products.

Keywords: persulfate; electrochemical activation, bromate formation; transformation of bromine

\section{$\underline{\text { FULL TEXT }}$}

(C) 2020 The Authors. Published by ESG (www.electrochemsci.org). This article is an open access article distributed under the terms and conditions of the Creative Commons Attribution license (http://creativecommons.org/licenses/by/4.0/). 